\title{
Toward Genomics-Based Breeding in C3 Cool-Season Perennial Grasses
}

\author{
Shyamal K. Talukder* and Malay C. Saha \\ Noble Research Institute, LLC, Ardmore, OK, United States
}

Most important food and feed crops in the world belong to the C3 grass family. The future of food security is highly reliant on achieving genetic gains of those grasses. Conventional breeding methods have already reached a plateau for improving major crops. Genomics tools and resources have opened an avenue to explore genome-wide variability and make use of the variation for enhancing genetic gains in breeding programs. Major C3 annual cereal breeding programs are well equipped with genomic tools; however, genomic research of C3 cool-season perennial grasses is lagging behind. In this review, we discuss the currently available genomics tools and approaches useful for C3 cool-season perennial grass breeding. Along with a general review, we emphasize the discussion focusing on forage grasses that were considered orphan and have little or no genetic information available. Transcriptome sequencing and genotype-by-sequencing technology for genome-wide marker detection using next-generation sequencing (NGS) are very promising as genomics tools. Most C3

OPEN ACCESS

Edited by:

Soren K. Rasmussen, University of Copenhagen, Denmark

Reviewed by: Leif Skot,

Aberystwyth University, United Kingdom Hamid Khazaei, University of Saskatchewan, Canada

*Correspondence: Shyamal K. Talukder sktalukder@noble.org

Specialty section: This article was submitted to Crop Science and Horticulture, a section of the journal Frontiers in Plant Science

Received: 19 March 2017 Accepted: 12 July 2017 Published: 26 July 2017

Citation: Talukder SK and Saha MC (2017) Toward Genomics-Based Breeding in C3 Cool-Season Perennial Grasses. Front. Plant Sci. 8:1317. doi: 10.3389/fpls.2017.01317 cool-season perennial grass members have no prior genetic information; thus NGS technology will enhance collinear study with other C3 model grasses like Brachypodium and rice. Transcriptomics data can be used for identification of functional genes and molecular markers, i.e., polymorphism markers and simple sequence repeats (SSRs). Genome-wide association study with NGS-based markers will facilitate marker identification for marker-assisted selection. With limited genetic information, genomic selection holds great promise to breeders for attaining maximum genetic gain of the cool-season C3 perennial grasses. Application of all these tools can ensure better genetic gains, reduce length of selection cycles, and facilitate cultivar development to meet the future demand for food and fodder.

Keywords: perennial grass, marker-assisted selection, genomic selection, next-generation sequencing, QTL mapping

\section{INTRODUCTION}

There are three photosynthetic carbon fixation pathways in plants. In one pathway, plants fix atmospheric carbon dioxide $\left(\mathrm{CO}_{2}\right)$ using Rubisco in Calvin cycle to produce a first stable product as three carbon compounds with no photosynthetic adaptation to reduce photorespiration. This group of plants is called C3 plants. In the second pathway, plants produce four carbon compounds as their first stable product and minimize photorespiration by separating the Calvin cycle from the light-dependent reaction using a physical barrier. This group of plants is called C4 plants. In the third pathway, plants use time to separate the light-dependent reaction instead of a physical barrier. This pathway was first discovered in the Crassulaceae family, thus it is called the Crassulacean Acid Metabolism (CAM) pathway. Plants which use this pathway are called CAM plants (Raines, 2011). 
The Poaceae family, commonly known as the grass family, is an important and widely distributed plant group on Earth (Stevens, 2001). Several members of this family are the most economically important plants supporting food, feed, industry, and lawns. The majority of these grasses belong to the C3 plant group (Araus et al., 2002). Bread wheat (Triticum aestivum) and rice (Oryza sativa), two out of the three most important staple food crops in the world, along with barley (Hordeum vulgare), rye (Secale cereale), oat (Avena sativa), and millet (Pennisetum glaucum), belong to the C3 grasses. Almost all cool-season perennial grasses used as forages and turf, i.e., orchardgrass (Dactylis glomerata), fescue (Festuca spp.), Kentucky bluegrass (Poa pratensis), perennial ryegrass (Lolium perenne), bentgrass (Agrostis spp.), Phalaris (Phalaris aquatica L.), intermediate wheatgrass (Thinopyrum intermedium), and sheepgrass [Leymus chinensis (Trin.)], are also C3 grasses (Bonos et al., 2006). Brachypodium distachyon, an important model plant species, is also a member of the $\mathrm{C} 3$ grasses.

Plant breeding has successfully contributed to crop improvement and feeding the Earth's increasing population since the beginning of the crop domestication process. Application of pre-genomics breeding technologies, combined with conventional breeding, have contributed significant yield improvement in various crops in the last century (Pérez-deCastro et al., 2012). Further increasing crop yields to fulfill the increasing demand of a Malthusian-predicted population will be a daunting task due to low genetic gains and various abiotic and biotic stresses that threaten food security and impose a tremendous challenge for the next century of agriculture (Kujur et al., 2013). Despite their importance as animal feed and the basis of healthy meat, milk, and other products for human consumption, perennial C3 cool-season grasses have received limited genetic improvement efforts. Though research attention is highly varied, the next level of genetic improvement for all cool-season C3 grasses is necessary based on increasing demand and improvement status.

Conventional breeding methods still are the most applied and efficient methodologies, but are not enough to cope with the increasing demand for both food and feed. Genomics breeding, a recent invention adopted by breeders, promises a paradigm shift by enhancing the association study of genotype versus phenotype (Tester and Langridge, 2010). The mainstay of genomic breeding is high-throughput DNA sequencing, which, combined with other molecular technologies [i.e., highthroughput genotyping, constructing high density genetic maps for marker phenotype association, marker-assisted selection (MAS), breeding by design and genomic selection (GS)], will be able to bring a breakthrough in food and feed production (Peleman and van der Voort, 2003; Varshney and Tuberosa, 2007; McMullen et al., 2009; Lorenz et al., 2011). Genomic technologies and platforms are currently available in several C3 cereal grass species (Xu et al., 2005; Tuberosa and Salvi, 2006; Araus et al., 2008; Mochida and Shinozaki, 2010; Bohra et al., 2014); thus, genomics-assisted breeding is becoming popular in those species. However, resources for most of the C3 perennial grasses are yet to be developed. This is the time to equip breeding programs with advanced genomic tools to enhance genetic gains using desirable alleles from various gene pools of diversified genetic bases.

In this review, we discuss the recent and relevant advancements of genomics tools and resources, and their applications in C3 grass breeding (Figure 1), along with summarized information of genome and breeding behavior (Table 1), particularly cool-season perennials. The objective is to provide an updated status of various genomics technologies along with their potential use in cool-season perennial grass breeding programs.

\section{GENOMICS TOOLS AND RESOURCES}

\section{Whole Genome Sequencing}

The availability of the whole genome sequence of a crop immensely helps to unlock the genome for necessary improvement through breeding. A complete reference genome sequence can potentially be used for discovering genes and regulatory elements, as well as sequence variation in the targeted DNA region. With the enormous advancement of nextgeneration sequencing (NGS) technology, the whole genome sequence of several C3 grass species (Brachypodium, rice, millet, wheat, and barley) are available (Goff et al., 2002; Yu et al., 2002; Vogel et al., 2010; Bennetzen et al., 2012; Consortium, 2012; Jia et al., 2013; Ling et al., 2013; Marcussen et al., 2014). Due to cost reduction and technology advancement, other cool-season perennial C3 grass genome sequences will be within reach (Byrne et al., 2011).

The arrival of NGS technologies has dramatically changed genomics research. The new technologies have reduced sequencing cost more than a 1000 times (Muir et al., 2016). Thus, many laboratories have started developing their own sequencing facilities. New third-generation sequencing platforms enhance the sequencing process by increasing the read length up to $10,000 \mathrm{bp}$ to substantially improve the assembly. They are available in PacBio RS (Pacific Biosciences ${ }^{1}$ ), Helicos $\left(\right.$ Helicos$^{2}$ ) or Ion Torrent (Life Technologies ${ }^{3}$ ). Recently, a long-read sequencing technology called Moleculo technology was launched by Illumina. Moleculo technology yields more than $10 \mathrm{~kb}^{4}$ individual sequence reads. The pitfall of the long-read sequencing platform is the positive correlation of sequence size with error rate (Nagarajan and Pop, 2013).

The large and repetitive nature of most cool-season grass genomes is the fundamental drawback for constructing a long continuous assembly. Moreover, polyploidy, heterozygosity, and subgenome existence cause additional problems during assembly. Therefore, third-generation long sequencing reads are extremely valuable for developing high quality assembly in such genomes. A large-scale sequence structure of DNA can be determined by third-generation mapping technologies. Mapping technologies

\footnotetext{
${ }^{1}$ http://www.pacificbiosciences.com

${ }^{2}$ http://www.helicosbio.com

${ }^{3}$ https://www.thermofisher.com/us/en/home/brands/ion-torrent.html

${ }^{4}$ https://www.illumina.com/science/technology/next-generation-

sequencing/long-read-sequencing.html
} 


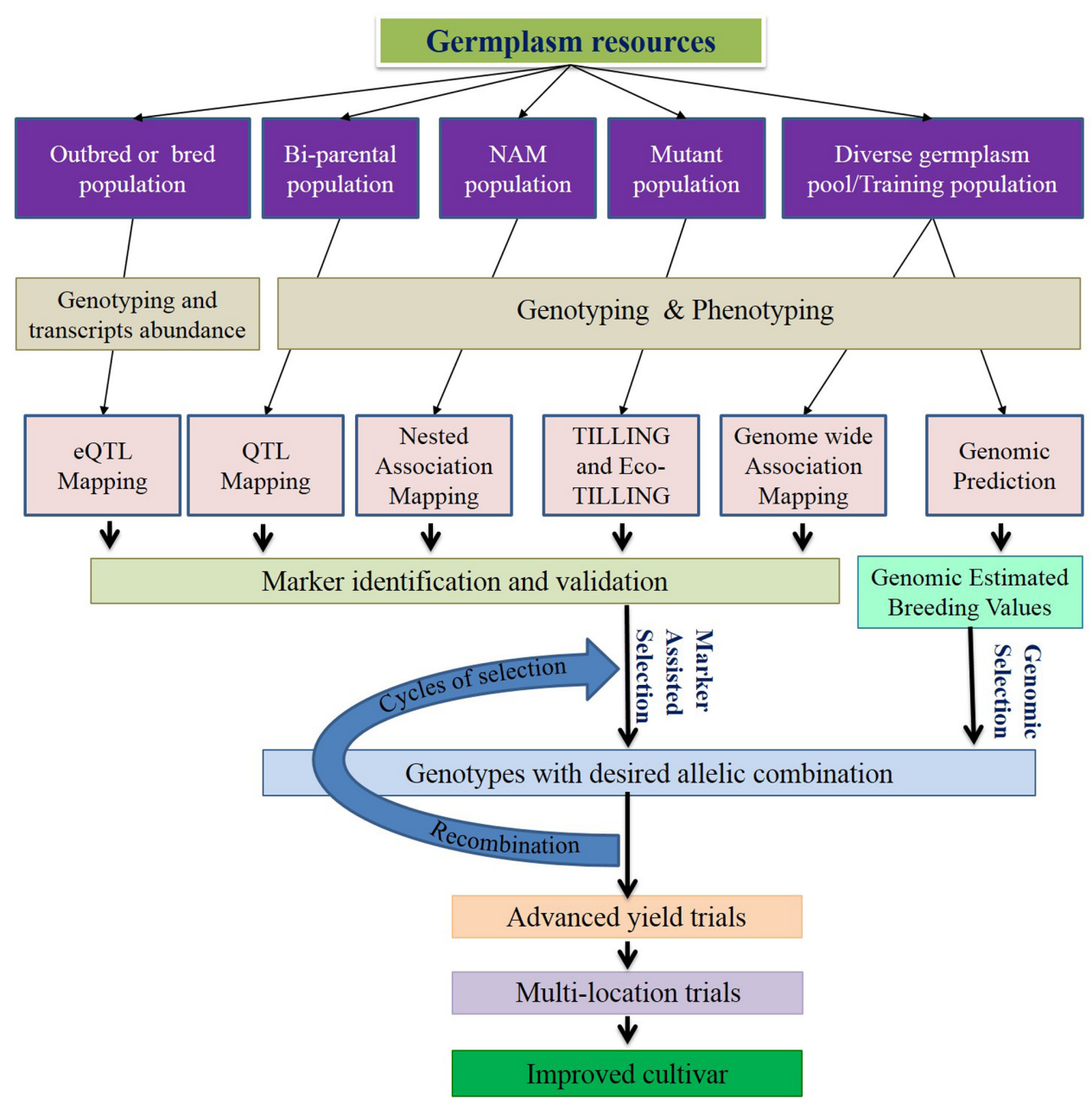

FIGURE 1 | Schematic diagram of genomics-assisted breeding. Genomics technologies help enhancing marker trait association for marker-assisted selection (MAS) and genomic selection (GS). Both MAS and GS speedup selection cycles, increases precision and improves genetic gain per year. Selection and recombination will be repeated multiple times before the yield trials to increase the favorable allele frequency. Incorporation of genomics to the recurrent selection strategies substantiates the effectiveness of breeding program.

like the Irys system from BioNano Genomics, Hi-C mapping of Dovetail Genomics and Chromium instrument from 10X Genomics will be very useful to generate high quality long contigs. The combined use of physical mapping and whole genome shotgun sequencing of single flow-sorted chromosomes like wheat might be fruitful to assemble a high quality draft of complex genomes (Kopecký and Studer, 2014). Hybrid assembly strategies of short, high-fidelity reads together with long reads from different sequencing platforms using hybrid error correction or self-correction algorithms might yield $99.9 \%$ base call accuracy (Lee et al., 2016; Zimin, 2016).

Among the cool-season grasses, only the perennial ryegrass draft genome sequence is available until now (Byrne et al., 2015). Draft genome sequencing and development of a genomic toolbox are underway in intermediate wheatgrass (Dorn, 2017a,b). Genomic research and information on other grasses like tall fescue, Kentucky bluegrass, orchardgrass, and bentgrass are rapidly developing. Guided de novo assembly of the whole genome using other sequenced C3 grasses might be helpful to functionally characterize those genomes. The advancement of sequencing throughput at lower cost will tremendously enhance the whole genome sequencing of individuals in the population to explore genetic variations among them. This will help detect millions of SNPs and genome-wide variations. Such high density markers will enable identification of candidate genes or markers useful for enhancing selection efficiency and breeding gains in breeding programs.

\section{Transcriptome Sequencing}

DNA sequencing and assembly of very large, complex polyploid grass genomes is still difficult with the currently available NGS technology. An alternative method for capturing the meaningful information of such genomes is whole genome next-generation transcriptome sequencing or RNA sequencing (RNA-seq) (Grabherr et al., 2011; Hirsch et al., 2014). Sampling from various developmental stages and/or tissues of diverse 
crops' genotypes enhances the generation of global transcript sequences along with variably expressed candidate genes (NCBI, GEO database). This has proven to be a powerful technology (Wang et al., 2009; Pingault et al., 2015) to capture differential gene expression, determine exon/intron boundaries ( $\mathrm{Lu}$ et al., 2010), study alternative splicing (Xie et al., 2015), identify post-transcriptional changes (de Alba et al., 2015), study transcription factors (Xu et al., 2014), microRNA, ribosomal RNA, transfer RNA, and small nuclear RNA (Rinn and Chang, 2012). This method has been successfully used to identify simple sequence repeats (SSRs) (Chapman, 2015) and SNP markers for assisting breeding in tall fescue (Talukder et al., 2015). The identification and usefulness of microsatellite markers using next-generation sequencing data was found promising in perennial ryegrass (Honig et al., 2017). In other cool-season perennial grasses, transcriptome sequences or other next-generation sequences might also be useful for genetic analysis and marker development. In a comparative transcriptome analysis, a stress-responsive protein has been identified in Lolium/Festuca species (Czaban et al., 2015). Recently, transcriptome analyses were done to study dwarfism to enhance dwarfing breeding in Kentucky bluegrass (Gan et al., 2016), drought stress response in creeping bentgrass (Ma et al., 2017), water stress (Talukder et al., 2015), lead (pb) stress (Li et al., 2017), and endophyte response in tall fescue (Dinkins et al., 2017), and to develop a unigene reference as a molecular breeding resource in Phalaris (Baillie et al., 2017). Markers developed from the reference transcript corresponding to the protein might be useful for MAS for stress tolerance. Approximately $72-87 \%$ of grass genes are predicted to be collinear (Mayer et al., 2009). Transcriptome sequences can be used to compare the conserved synteny of sequenced C3 grasses for gene/transcriptome quantification (Kopecký and Studer, 2014). Similarly, using the reference transcripts of identified SSRs or SNPs, functional importance as well as localized gene function might be explored for genomics-assisted breeding in understudied C3 perennial grasses (Talukder et al., 2015) along with best studied ones.

An emerging new approach called genome zipping has been developed for under studied and complex grass genomes. This approach works based on the high degree of synteny among the Poaceae grasses along with numerous genomics resources of various grass species. It usually identifies and organizes the syntenic region of sequenced genomes based on a genetic linkage map of the targeted species. The information from sequenced genomes is then integrated into an ordered gene model and resolves species-specific local arrangement (Pfeifer et al., 2013; Poursarebani et al., 2013; Kopecký and Studer, 2014). Among the cool-season grasses, the genome zipper approach was first implemented in perennial ryegrass and was proven useful for map-based cloning and QTL fine mapping (Brazauskas et al., 2013; Pfeifer et al., 2013; Arojju et al., 2016). Using assembled reference transcripts of NGS-based transcriptome sequences, the genome zipper approach would be very useful to generate a genome draft. The retrieved functional gene and marker information will enhance genomics-assisted breeding.

\section{Mutational Genomics}

Genetic variation is the pillar of plant breeding success. Various techniques have been developed and used to create mutant collections. The transferred DNA-tagged lines and transposontagged lines have been used to develop mutant collections in Arabidopsis (The Arabidopsis Information Resource ${ }^{5}$ ) and rice (International Rice Functional Genomics Consortium). RNA interference was used to create gene-specific mutant collections in Arabidopsis ${ }^{6}$. Using a reverse genetics approach called Targeting Induced Local Lesions in Genomes (TILLING), the allelic variations of an artificial mutant collection were identified (Till et al., 2003). A similar approach to identifying allelic variation in a natural germplasm collection is called ecotype TILLING (EcoTILLING) (Comai et al., 2004). Both methods use CEL 1 or Endo 1 to recognize and cut double helix DNA to identify allelic variants in a certain genomic region (Till et al., 2004). The frequency and efficiency of these methods significantly rely on available NGS sequences yielded from gene expression studies (Pérez-de-Castro et al., 2012). Both methods were successfully implemented in C3 Grasses. TILLING has been implemented in barley (Caldwell et al., 2004), while EcoTILLING has been applied to rice (Kadaru et al., 2006), wheat (Wang et al., 2008), and barley (Mejlhede et al.,

\footnotetext{
${ }^{5}$ http://www.arabidopsis.org

${ }^{6}$ http://www.agrikola.org
}

TABLE 1 | Name, genome information, and breeding behavior of commonly used cool-season C3 perennial grasses.

\begin{tabular}{|c|c|c|c|c|c|}
\hline Common name & Scientific name & Genome size & Ploidy level & Breeding system & Chromosome number \\
\hline Bromegrasses/Smooth brome & Bromus inermis & 6.0-26.0 Gb & Diploid to decaploid & Open pollination & $2 n=(2 x-10 x)=(14-70)$ \\
\hline Kentucky bluegrass & Poa pratensis & $6.9-12.80 \mathrm{~Gb}$ & Pentaploid to quindecaploid & Open pollination & $2 n=(5 x-15 x)=(35-105)$ \\
\hline Tall fescue & Festuca arundinacea & $5.25-5.83 \mathrm{~Gb}$ & Hexaploid & Open pollination & $2 n=6 x=42$ \\
\hline Orchardgrass & Dactylis glomerata & $4.31 \mathrm{~Gb}$ & Tetraploid & Open pollination & $2 n=4 x=28$ \\
\hline Perennial ryegrass & Lolium perenne & $2.7 \mathrm{~Gb}$ & Diploid & Open pollination & $2 n=2 x=14$ \\
\hline Reed canarygrass & Phalaris arundinacea & $4.96-5.17 \mathrm{~Gb}$ & Tetraploid/hexaploid & Open pollination & $2 n=(4 x-6 x)=(28-42)$ \\
\hline Timothy & Phleum pratense & NA & Diploid/hexaploid & Open pollination & $2 n=6 x=42$ \\
\hline Bentgrass & Agrostis spp. & $2.7-2.8 \mathrm{~Gb}$ & Tetraploid & Open pollination & $2 n=4 x=42$ \\
\hline Intermediate wheatgrass & Thinopyrum intermedium & $12.6 \mathrm{~Gb}$ & Hexaploid & Open pollination & $2 n=6 x=42$ \\
\hline
\end{tabular}

$N A$, the information about genome size was not found. 
2006). In recent years, mutagenesis has advanced significantly. Various site-directed or site-specific nucleases (SDNs/SSNs), such as zinc-finger nucleases, TALENs or CRISPR/Cas9, have been developed and used as mutagenic agents to discover potential alleles using forward and reverse genetics approaches (Pradhan et al., 2015; Nogué et al., 2016). Most cool-season grasses have large complex genomes with scarce genomic information. Thus, the successful application of these techniques should be followed by QTL identification.

\section{High-Throughput Molecular Markers}

Plant breeders predominantly like SSR and SNP markers for marker-assisted breeding. NGS technology has made it possible to rapidly sequence multiple individuals for minimum cost. Powerful computational pipelines and various software are greatly enhancing the mining of NGS sequences for genetic variations, i.e., SSRs and SNPs. Due to abundance, reproducibility, amenability to automation and tremendous cost effectiveness, SNPs are becoming the marker of choice to plant breeders (Pérez-de-Castro et al., 2012). Massive re-sequencing and genome-wide SNP discovery have been performed in Arabidopsis (Weigel and Mott, 2009). Aligning reads from the 3000 Rice Genome Project, 20 M SNPs have been identified and provided in a SNP-Seek system ${ }^{7}$ (Alexandrov et al., 2015). Recently, a 90k SNPs genotyping array was developed in wheat and found to be well distributed in the genome (Wang et al., 2014). More recently, $4 \mathrm{M}$ SNPs have been identified and characterized in the wheat genome. These are available in a generic genome browser, GBrowse, at www.wheatgenome.info (Lai et al., 2015). SNP identification is challenging in complex polyploid and/or outcrossing heterozygous genomes due to mis-assembly and false positive SNP identification (Mason, 2015). The presence of reference genomes of the species facilitates the reduction of alignment difficulties and thus increases the accuracy of SNP identification along with genome position (Ruperao and Edwards, 2015). SNP identification efficiencies of crops with no prior genome information can be facilitated by incorporating several paired end sequencing techniques. Other ways to facilitate SNP identification are transcriptome sequencing, genotype by sequencing (GBS), and exon capture. Transcriptome sequencing has been applied to SNP and SSR identification in many crops with limited genetic information and no reference genome sequences, i.e., tall fescue (Talukder et al., 2015), red clover (Yates et al., 2014), camelina (Mudalkar et al., 2014), oaks (Torre et al., 2014), turmeric (Sheeja et al., 2015), mung bean (Chen et al., 2015), and lupin (Kamphuis et al., 2015). Identified markers, as well as their reference transcript, might be aligned to the closely related sequenced genome for further exploration of the targeted markers (Talukder et al., 2015).

Genotype by sequencing is a rapid, robust and cost-effective genotyping technology that performs genome-wide molecular marker discovery by reducing genomic complexity. Application of this technology in plant species without prior genetic resources for genomic research has paved the way for researchers to adopt GBS as a high-throughput marker technology for orphan crops

${ }^{7}$ http://snp-seek.irri.org/ as well. This method has been validated to be used in diversity (Elshire et al., 2011) and association studies (Hegarty et al., 2013; Morris et al., 2013) as well as advanced breeding application (Poland et al., 2012; Poland, 2015). A cost-effective targeted amplicons-based GBS approach was found very effective for genotyping perennial ryegrass and Italian ryegrass (Pembleton et al., 2016). Along with marker identification, GBS is a powerful tool to calculate genome-wide allele frequency of a particular locus. This can be a very effective tool for various forage, lawn, and turf grass breeding (Byrne et al., 2013).

Restriction site-associated DNA sequencing (RADSeq) is also a genotype-by-sequencing approach to marker discovery and can identify widely distributed markers across the genome using NGS technology (Baird et al., 2008; Hohenlohe et al., 2010). Akin to GBS, it also reduces the genome complexity by subsampling the restriction site of specific enzymes and can provide genomics-scale insights for orphan crops with no prior genomic information available. Many SNP-based genetic maps and association studies have been reported using a RAD sequencing platform in understudied grasses (Chutimanitsakun et al., 2011; Hegarty et al., 2013; Wang et al., 2013; Slavov et al., 2014; Varshney, 2015; Wang F. et al., 2015).

Exome capture is a newly emerging genomics tool for marker identification. It is rapid, cost effective and applicable to forage, lawn, and turf grasses with limited genetic/genomic information. Exome capture was initially reported in human genomics. In this technology, only protein coding regions of a genome are captured and separated by hybridizing genomic DNA with biotinylated oligonucleotide probes complementary to targeted exons, thus reducing the unnecessary junk part of the genome for sequencing (Choi et al., 2009; Ng et al., 2009). Exome capture and SNP identification has been successfully performed in many crops, i.e., barley (Mascher et al., 2013), rice (Henry et al., 2014), and wheat (Winfield et al., 2012; Allen et al., 2013). Capturing assays developed for one species can be applied to related species to enrich the genomic region (Mascher et al., 2013). Following this idea, switchgrass (Panicum virgatum) exome capture probes were used to perform exome capture sequencing in bermudagrass (Cynodon dactylon) genotypes for SNP calling and GWAS study (Malay Saha, Noble Research Institute, LLC). Both the abovementioned species belong to the C4 grasses; however, non-model C3 grass species can also be studied and compared with other C3 grasses with existing reference sequenced genomes.

\section{High Density Genetic Maps}

The advancement of genomics technology has significantly enhanced the development of high density genetic maps even in understudied crops with large, complex genomes. Integration of NGS and high-throughput genotyping platforms significantly increased marker density in genetic maps. Construction of SNP-based genetic maps is faster and effective for crops with intense genetic information. The Illumina GoldenGate has been the most widely used platform for SNP genotyping, while Sequenom MassARRAY platform-based SNP-typing assays are becoming popular as well (Oliver et al., 2011; Chagné et al., 2015). SNP-based high density linkage and transcriptome map 
construction using NGS data has been successful in wheat (Wu et al., 2015; Holtz et al., 2016), rice (Xie et al., 2010; Zhang et al., 2015), maize (Liu et al., 2010; Mahuku et al., 2016), barley (Chutimanitsakun et al., 2011; Obsa et al., 2016), perennial ryegrass (Pfender et al., 2011; Paina et al., 2016; Velmurugan et al., 2016), orchardgrass (Zhao et al., 2016), intermediate wheatgrass (Kantarski et al., 2017), and zoysia grass (Zoysia japonica) (Wang F. et al., 2015). NGS-derived SNP-based genetic maps are useful for comparative mapping and have great potential for cool-season perennial grasses with limited genomic information available. These SNP markers can be aligned to genomes or linkage maps of closely related C3 grasses like Brachypodium, rice, wheat, and barley. The comparison of high density SNP maps was useful for barley with wheat and rice (Close et al., 2009; Sato et al., 2009), switchgrass with foxtail millet (Setaria italica) (Daverdin et al., 2014) and muscadine grape (Vitis rotundifolia) with European bunch grape (Vitis vinifera) (Owens, 2015). Comparative genetics analysis can also be performed using SSRs and other molecularmarker-based maps (Paolucci et al., 2010; Hudson et al., 2012; Dierking et al., 2015). Recently, genome-wide SSR sequences were detected from nine completely sequenced grass species (Oryza sativa L. ssp. japonica, Oryza sativa L. ssp. Indica, Zea mays, Sorghum bicolor, Brachypodium distachyon, Setaria italica, Phyllostachys heterocycla, Triticum urartu, and Aegilops tauschii). The descriptions of the SSRs were provided in the Poaceae SSR Database ${ }^{8}$ in terms of abundance, density, base ratio of different motifs, and genomic elements, i.e., exon, intron, and UTR (Wang Y. et al., 2015). Genetic maps combining both SSRs and NGS-SNPs would thus be very effective for MAS. Co-localized SSRs and SNPs will provide additional information and validation through comparative genomics and genetics. Genetic maps using mixed marker systems have been reported and found promising in wheat (Talukder et al., 2014; Wu et al., 2015), pear (Pyrus spp.) (Wu et al., 2014), common bean (Phaseolus vulgaris L.) (Schmutz et al., 2014), faba bean (Vicia faba L.) (Satovic et al., 2013), orchardgrass (Zhao et al., 2016), and many other crops. SNP identification in outcrossing polyploids is very critical. Identification of a high number of false positive SNPs is highly likely. False positive SNPs can be an obstacle during genetic linkage map construction. SSR markers thus can be used as references to construct accurate linkage maps. However, construction of high density linkage maps using only SSR markers will be expensive and time consuming. Thus, high density genetic linkage maps using a mixed marker system might be very useful for cool-season perennial grasses like tall fescue, orchardgrass, Kentucky bluegrass, perennial ryegrass and bentgrass.

\section{Phenomics for Genomics-Assisted Breeding}

Breeding success relies on capturing the best genetic variation from the germplasm resources. Breeders need to manage very large breeding populations to develop superior varieties. NGS-based high-throughput genotyping has facilitated a way

${ }^{8}$ http://biodb.sdau.edu.cn/pssrd/index.html to incorporate 1000 s of genotypes in the mapping population. The advancement of high-throughput phenotyping (HTP) technology cannot keep pace with the high-throughput genotyping and thus has been considered a limiting factor for next-generation genomics-assisted breeding (Houle et al., 2010). Recently the importance of HTP has been emphasized. There are fully automated and precisely controlled phenotyping platforms available in some public plant research institutions, i.e., the USDA ${ }^{9,10}$, the Australian Plant Phenomics Facility ${ }^{11}$, and the European Plant Phenotyping Network ${ }^{12}$, with remote sensing facilities to monitor plant growth and performance (Araus and Cairns, 2014). Variability of environment, soil and drought conditions in the field cannot be provided to plants growing in pots under controlled-environmental conditions. Phenotyping for drought in a pot is incredibly difficult. The gradual decline of soil moisture in the field is associated with increased mechanical encumbrance, which is difficult to imitate in pots (Cairns et al., 2011). Therefore, the translational ability of controlled-environment-phenotyping results in the field is very low. Moreover, the variety development process involves multi-environment trials where plants are exposed to various stresses throughout their life cycle. As a result, an increased effort has been made to implement HTP in the field. Usually, HTP platforms rely on image capturing to phenotype plants. Several review articles have been published describing imaging techniques, novel sensors, image analysis, modeling, robotics, and data mining for both ground-based and aerial systems HTP platforms (Cobb et al., 2013; Costa et al., 2013; Araus and Cairns, 2014; Goggin et al., 2015; Humplík et al., 2015). Various phenomobiles have been used in recent years as ground-based HTP. Phenomobiles are modified vehicles with global positioning systems (GPS) combined with various sensors. This type of phenomobile is effective for small-scale breeding programs to produce plot-level data. The phenomobile used in cotton field phenotyping contains four sensors for measuring canopy height, reflectance and temperature on four rows simultaneously at a rate of 0.84 ha per hour (Andrade-Sanchez et al., 2014). A mobile platform with hyperspectral passive spectrometer to predict crude protein in wheat, tall fescue, and bermudagrass was also successful (Pittman et al., 2016). Prediction of biomass yield, the most important trait for C3 grass breeding will be more accurate. The limitations of phenomobiles are time consumption and data processing. Compared to ground-based HTP, aerial HTP is much faster and can characterize all plots in a trial within a minute using various platforms, i.e., phenotowers (Rascher et al., 2011), blimps (Losos et al., 2013), and unnamed aerial platforms (UAP) such as airplanes and polycopters. However, aerial HTP involves high cost, and superior mechanical and data processing skills. Overall, HTP clearly demonstrates the potential of non-destructive phenotyping with precision and

\footnotetext{
${ }^{9}$ https://nifa.usda.gov/sites/default/files/resources/Whitepaper_finalUSDA.PDF

${ }^{10} \mathrm{http}: / /$ www.wheatgenetics.org/downloads/Projects/HTP_ProjectNarrative_ 20130219.pdf

${ }^{11}$ http://www.plantphenomics.org.au/

${ }^{12} \mathrm{http}: / /$ www.plant-phenotyping-network.eu/eppn/structure
} 
pace in a tractable way (Poland, 2015). Upon application in breeding programs, HTP will balance the genotype-tophenotype dataset and provide raw materials for next-generation breeding.

\section{GENOMICS APPROACHES FOR C3 PERENNIAL GRASS BREEDING}

\section{Genome-Wide Association Studies (GWAS)}

Plant breeders struggle to capture and transfer genetic variability of target traits. In most cases, the existing genetic variation remains untapped due to lack of resources in breeding programs to allow the utilization of variability in the available germplasm. High-throughput genotyping platforms permit genome-wide marker detection for high resolution marker profiling and are already being used in a few C3 grasses, i.e., orchardgrass (Zeng et al., 2017) and perennial ryegrass (Ruttink et al., 2015), for genome-wide association studies (GWAS). GWAS is an excellent tool that has been used to identify genetic variants associated with traits of interest. GWAS provides understanding of genome function as well as allelic architectures of complex traits (Huang et al., 2010). With advanced genotyping technology, GWAS is becoming a very powerful tool for crop breeding enhancement. In the case of autogamous homozygous or clonally maintained allogamous species, a GWAS panel might be a permanent resource for the crop (Huang and Han, 2014). Nested Association Mapping (NAM), another genome-wide association strategy that simultaneously exploits the advantage of linkage analysis and association mapping, can be an excellent tool to capture marker trait association (Yu et al., 2008). There is no report of NAM in any $\mathrm{C} 3$ cool-season perennial grasses. The major limitation is that it is generally not possible to produce inbred lines in outbreeding crops and maintain seeds for the research community. Pseudo F2 families' development and clone maintenance of those families can be done in these crops. A modified chain-cross protocol was used to develop a NAM population in switchgrass, a C4 outcrossing polyploid species (Ali et al., 2016). Developing and maintaining such population are usually expensive and time consuming. However, once developed, the population could be an asset for grass breeding programs. The coolseason C3 perennial grasses are mostly allogamous; therefore, capturing linkage disequilibrium (LD) of those crops requires high resolution marker information in the association panel. Simultaneously, the size of panel should be large enough to maximize the statistical power for rare allele detection. Genomewide association studies have been implemented in perennial ryegrass and tall fescue among the allogamous $\mathrm{C} 3$ grasses (Skøt et al., 2005; Yu et al., 2013, 2015; Aleliūnas et al., 2015; Lou et al., 2015). Using high-throughput genotyping platforms, i.e., GBS and RAD seq, an enormous amount of SNPs can be identified for GWAS to capture the LD decay in C3 grass panels with limited genetic information available. Thus, GWAS can be a powerful tool for those orphan crops for practical genomicsassisted breeding.

\section{Mapping QTL and Identification of Markers Linked to the Traits}

Next-generation sequencing significantly enhanced genotyping platforms for high resolution marker identification and accommodation in the genetic map for QTL study (Figure 1). It is possible to detect markers tightly linked to the target traits by increasing the genome coverage of marker density in optimum size mapping population. The effective size of the mapping population is crucial in capturing recombinant events. Increasing markers in a small population will make many of the markers redundant or uninformative. Along with the increasing accuracy of QTL detection, the number of QTL studies is growing at an impressive pace. During the last 22 years, 133 QTL studies on yield and 361 QTL studies on disease resistance reported 1,600 and 4,300 QTL, respectively, in wheat (Salvi and Tuberosa, 2015). It has been clear from empirical analysis that a large number of QTL have a smaller effect while a smaller number have a larger effect (Flint and Mackay, 2009; Kliebenstein, 2010). This observation complies with the Fisher-Orr model, which describes strong alleles segregating for a loci quickly get fixed and disappear from the population while weak alleles keep segregating (Orr, 2005). Thus, complex traits like yield in elite cultivars are prone to be detected with minor effect QTL. However, many major effect QTL also have been identified, validated, cloned and successfully utilized by breeders for yield, plant height, heading date, flowering time, drought tolerance, disease resistance, salt tolerance, and nematode resistance in many crops, i.e., rice, wheat, sorghum, chickpea, maize, and soybean (Xing and Zhang, 2010; Griffiths et al., 2012; Salvi and Tuberosa, 2015). Besides the elite members of the $\mathrm{C} 3$ grasses, QTL studies also have been reported in perennial ryegrass (Armstead et al., 2004; Jensen et al., 2005; Muylle et al., 2005; Turner et al., 2006; Sim et al., 2007; Schejbel et al., 2008; Pearson et al., 2011; Khaembah et al., 2013; Ma et al., 2014; Paget et al., 2014; Kundu et al., 2015), meadow fescues (Ergon et al., 2006; Alm et al., 2011), creeping bentgrass (Jespersen et al., 2016), and orchardgrass (Zhao et al., 2016). Few linkage maps have been reported in tall fescue (Saha et al., 2005; Dierking et al., 2015). Recently a consensus genetic map using GBS markers has been published in intermediate wheatgrass (Kantarski et al., 2017). However, there is not much QTL mapping information available for other cool-season perennials.

Overall, QTL information in various traits has tremendous potential to enhance plant breeding. Using NGS-based SNP information in accordance with SSRs may identify high powered QTL and resolve the linkage phase between marker and the QTL alleles.

A new strategy of QTL mapping based on abundance of measurable transcript levels in diverse mapping populations is emerging. In this method, DNA polymorphisms can be identified that control single/multiple gene expression levels (Schadt et al., 2003). Advancement of sequencing technologies, accompanied with reduced cost, opened the door for transcriptome sequencing or expression microarrays of large biparental/GWAS populations. Put simply, expression levels 
of transcripts/genes are measured and used as the phenotype to find the marker-transcript association. There is no report of eQTL study in C3 perennial grass. With next-generation sequencing help, eQTL holds great promise for effective marker identification to enhance MAS (Figure 1).

\section{Marker-Assisted Selection}

Marker-assisted selection can enhance a breeding program by selecting plants in an early generation, thereby reducing breeding time (Figure 1). It is the oldest and most widely used technology to be considered genomics-assisted breeding. The success of MAS relies on identification of markers tightly linked with the genes or genomic region (QTL) of a target trait. With the recent advancement of the NGS-based genotyping platform, it is possible to identify markers very close to the target region. The rule of thumb for MAS is "The closer the marker to the gene/QTL, the more effective the MAS." The linked markers are applied to select introgressed individuals with desired allelic combinations in early generations when phenotypic evaluation is not fruitful. Recombination may displace a closely linked intergenic marker; thus intragenic markers called functional markers are always preferable for MAS. In this case it is highly unlikely to displace the marker from the gene through recombination. Because of abundance, randomness, and polymorphism in the genome, NGS-based SNPs have a high chance of being linked as functional markers. Similarly, NGS markers can identify individuals with critical recombination break points to eliminate linkage drags for important traits (Fukuoka et al., 2009; Venuprasad et al., 2012). Therefore these markers enhance gene-assisted breeding, eliminating the possibility of losing the trait by recombination as well as expelling the linkage drag from desired elite lines (Pérez-de-Castro et al., 2012; Varshney et al., 2014).

Traits with both simple and complex inheritance (i.e., disease, pest and insect resistance; heat, drought and salt tolerance; and grain and biomass yield and quality) are being used for MAS in various C3 grasses. Breeders usually use MAS for introgression of minor alleles to the elite germplasm, gene pyramiding and improve complex traits with phenotyping difficulties (Varshney et al., 2014).

C3 grasses with limited genetic resources can be easily studied with NGS-based markers and background genetic information retrieved through collinear study with other wellstudied C3 grasses. A well-studied marker system has already been developed in perennial ryegrass suitable for MAS (KöLliker et al., 2005; Rajicic et al., 2015). Other cool-season perennial grasses can be syntenized with Brachypodium, rice, and wheat for validation and functional information of the linked marker. A few 1000 SSRs and SNPs have been identified in tall fescue by Talukder et al. (2015). They found very good distribution in the Brachypodium genome. They also found more than 60 percent genome similarity between the tall fescue transcriptomes and the Brachypodium genome. The Saha group (Grass Genomics Laboratory) at the Noble Research Institute is in the process of building a marker database for tall fescue, which might also be useful for other cool-season C3 perennial grasses. SSR markers associated with forage digestibility were identified and used in a MAS program. Synthetic populations have been developed by random mating of MAS genotypes from a breeding population of tall fescue. The population looks promising. Evaluations of the synthetic population at multi-location field trials are in progress. Chloroplast markers discriminating Mediterranean and Continental morphotypes were identified in tall fescue and are being used at the Noble Research Institute for tall fescue morphotype identification. Most cool-season perennial grasses are outcrossing in nature. Allele accumulation by recurrent selection is time and labor intensive for outcrossing species. Tightly linked markers would help reduce the number of genotypes in every cycle and enhance phenotyping efficiency, as well as intensify favorable alleles in the population. Thus there is great promise for MAS breeding in the cool-season C3 grasses. Many of the perennial C3 members are not genetically well documented. Meanwhile, the success of genomics-assisted breeding solely depends on the gene or QTL identification for various traits of interest. Frequent genetic study of marker/gene/QTL identification in those orphan grasses will definitely enhance breeding programs for necessary improvement.

\section{Genomic Selection (GS)}

Genomic selection is a form of MAS that attempts to eliminate the limitations of MAS. Usually MAS success depends on QTL detection, which has been questioned for certain limitations in both biparental and genome-wide association mapping strategies. Firstly, the allelic distribution of a breeding program cannot be covered by a biparental mapping population, and generated information is merely applicable for the breeding program without proper validation. Moreover, the accuracy and marker effect are mostly overestimated in biparental QTL mapping. Genome-wide association studies reduced the limitation of population development and allele frequency limitation in biparental QTL mapping; however, low heritability, few largeeffect QTL, confounding population structure and QTL with overestimated effects are still limitations of MAS (Holland, 2007; Heffner et al., 2009).

In GS, all marker data in the population are utilized as breeding value predictors. A prediction model is developed based on marker information, phenotyping information and pedigree information of the training population, which provides genomic estimated breeding values (GEBVs) for all genotyped germplasm in the breeding population to predict plant performance in the breeding program (Figure 1) (Meuwissen et al., 2001). Prediction accuracy relies on the genetic relationship between the training population and the breeding population, phenotyping accuracy, age of the training population, heritability of the predicted trait and breeding population structure (Jannink et al., 2010; Crossa et al., 2014; Varshney et al., 2014). Providing pedigree information and genome-wide high density marker deployment can definitely increase the prediction accuracy of GS. As we discussed earlier, many C3 grass species lack substantial genetic information. However, GS does not require prior genetic information, and, thus, the technique is directly applicable for those grass breeding programs with limited or no genetic information. The main expected benefits of GS for these crops are to increase selection efficiency, increase average 
genetic gain per year, reduce time of breeding cycle and reduce breeding cost. Almost all the commonly used C3 perennial grasses are outcrossing, and limited knowledge of LD and effective population size $\left(N_{e}\right)$, constraints in SNP discovery and validation, prediction accuracy, and increased annual inbreeding rate are the major limitations in GS of the target grasses (Forster et al., 2014). Effective GBS method development for determining allelic dosages is still an issue (Hayes et al., 2013). Another problem of such crops might be the stagnation of the training population. Considering the economic investment, most programs may use part of their breeding program as the training population which might have experienced directional selection for a few generations; thus genetic variance of the markers might be reduced (Simeão Resende et al., 2014). The complexity of controlling genetic variation might be navigated by using accurate genotyping assay and a higher number of markers (Fè et al., 2016; Grinberg et al., 2016). In this regard, recently developed SNP identification pipelines that are effective for SNP identification in polyploid genomes might be helpful. Being outcrossing, most of the cool-season perennial grasses might have lower LD and greater complexities to study genetic variations. The problem of lower LD in perennial ryegrass could be reduced by using structure and family information in the breeding population (Fè et al., 2015). Shortening breeding cycle time in GS may enhance the annual inbreeding rate (Lin et al., 2016). To control this type of inbreeding in GS of outbreeds, Lin et al. (2017) proposed three types of heuristic approaches, i.e., controls during mate allocation, during selection, and simultaneous selection and mate allocation. The lower prediction accuracy of GS might be increased by increasing and updating the population at frequent intervals. However, larger populations with continuous updates will increase the cost per unit gain. Estimating breeding value of an individual based on performance of its relatives may provide a reasonably higher genetic gain per year, as well as prediction accuracy. This approach may be problematic in cool-season perennial grass breeding due to unknown pedigree of many individuals. Moreover, performance of the individual family needs to be measured as plot-family mean basis thus; higher genotyping and phenotyping cost will be involved in this system. Prediction accuracy and genetic gain can be increased to a reasonable level in the miniplot genotyping system by increasing plot number and reducing selection intensity. However, that may increase the cost of phenotyping as well (Lin et al., 2017). In reality, it is highly likely that the genotyping cost will be reduced at a significantly higher pace than the phenotyping cost. The breeding programs will be more organized in future in keeping track of pedigree. Therefore,

\section{REFERENCES}

Aleliūnas, A., Statkevičiūtè, G., Jonavičienė, K., Kemešytė, V., and Brazauskas, G. (2015). "Evaluation of perennial ryegrass association mapping population for freezing tolerance traits," in Molecular Breeding of Forage and Turf, eds H. Budak and G. Spangenberg (Cham: Springer), 9-18.

Alexandrov, N., Tai, S., Wang, W., Mansueto, L., Palis, K., Fuentes, R. R., et al. (2015). SNP-Seek database of SNPs derived from 3000 rice genomes. Nucleic Acids Res. 43, D1023-D1027. doi: 10.1093/nar/gku1039 single genotype genotyping might yield more economic gain per unit of genetic gain. However, prediction accuracy comparison of plot-family-based allele frequency of miniplots using family-trait mean and individual allele of single genotype genotyping using individual trait were found equivalent in a GS model (Munoz, 2017). A relatively higher number of alleles are accommodated in the prediction model for family-based allele frequency. This type of prediction model might be highly useful because developing a synthetic variety based on a greater amount of allelic information might increase the sustainability of a released cultivar. Till now, there have not been many reports about the application of GS in C3 cool-season perennial grasses except perennial ryegrass, but with the advent of NGS-based genotyping platforms, breeders will be encouraged to adopt GS for varietal improvement.

\section{CONCLUSION}

The advancement of genomics resources and tools has shown tremendous enhancement in the breeding program. Combined with conventional breeding, genomics tools and resources will dramatically hasten the achievement of expected genetic improvement of important grasses, most significantly some genetically orphan cool-season C3 perennial grasses. In the near future, breeding programs will be large enough to maintain 1000s of lines with rich genomic resources. Concomitantly, focus has already been given to HTP (Phenomics). Once genomics and phenomics are on the same page and with fully developed data management systems, vast knowledge about genomes will be fully mined; thus, genomics tools will uphold the promise of ensuring food security for the population.

\section{AUTHOR CONTRIBUTIONS}

ST has written the manuscript. MS has contributed to provide idea, information, and organization for writing, as well as writing some portion of the manuscript.

\section{ACKNOWLEDGMENTS}

The authors highly appreciate Courtney Leeper, writer/copy editor, Noble Research Institute, and Jackie Kelley for proofreading and editing the manuscript for English and grammar.

Ali, S., Chang, J., Serba, D. D., Bhandari, H. S., Bartley, L., and Saha, M. C. (2016). "Cataloging natural allelic variations in switchgrass (Panicum virgatum L.) NAM parental genomes," in Proceedings of the International Plant \& Animal Genome XXV conference, San Diego, CA.

Allen, A. M., Barker, G. L., Wilkinson, P., Burridge, A., Winfield, M., Coghill, J., et al. (2013). Discovery and development of exome-based, codominant single nucleotide polymorphism markers in hexaploid wheat (Triticum aestivum L.). Plant Biotechnol. J. 11, 279-295. doi: 10.1111/pbi. 12009 
Alm, V., Busso, C. S., Ergon, Å., Rudi, H., Larsen, A., Humphreys, M. W., et al. (2011). QTL analyses and comparative genetic mapping of frost tolerance, winter survival and drought tolerance in meadow fescue (Festuca pratensis Huds.). Theor. Appl. Genet. 123, 369-382. doi: 10.1007/s00122-011-1590-z

Andrade-Sanchez, P., Gore, M. A., Heun, J. T., Thorp, K. R., Carmo-Silva, A. E., French, A. N., et al. (2014). Development and evaluation of a field-based highthroughput phenotyping platform. Funct. Plant Biol. 41, 68-79. doi: 10.1071/ FP13126

Araus, J., Slafer, G., Reynolds, M., and Royo, C. (2002). Plant breeding and drought in C3 cereals: What should we breed for? Ann. Bot. 89, 925-940. doi: 10.1093/ aob/mcf049

Araus, J. L., and Cairns, J. E. (2014). Field high-throughput phenotyping: the new crop breeding frontier. Trends Plant Sci. 19, 52-61. doi: 10.1016/j.tplants.2013. 09.008

Araus, J. L., Slafer, G. A., Royo, C., and Serret, M. D. (2008). Breeding for yield potential and stress adaptation in cereals. Crit. Rev. Plant Sci. 27, 377-412. doi: 10.1080/07352680802467736

Armstead, I. P., Turner, L. B., Farrell, M., Skøt, L., Gomez, P., Montoya, T., et al. (2004). Synteny between a major heading-date QTL in perennial ryegrass (Lolium perenne L.) and the $\mathrm{Hd} 3$ heading-date locus in rice. Theor. Appl. Genet. 108, 822-828. doi: 10.1007/s00122-003-1495-6

Arojju, S. K., Barth, S., Milbourne, D., Conaghan, P., Velmurugan, J., Hodkinson, T. R., et al. (2016). Markers associated with heading and aftermath heading in perennial ryegrass full-sib families. BMC Plant Biol. 16:160. doi: 10.1186/ s12870-016-0844-y

Baillie, R. C., Drayton, M. C., Pembleton, L. W., Kaur, S., Culvenor, R. A., Smith, K. F., et al. (2017). Generation and characterisation of a reference transcriptome for phalaris (Phalaris aquatica L.). Agronomy 7:14. doi: 10.3390/ agronomy7010014

Baird, N. A., Etter, P. D., Atwood, T. S., Currey, M. C., Shiver, A. L., Lewis, Z. A., et al. (2008). Rapid SNP discovery and genetic mapping using sequenced RAD markers. PLoS ONE 3:e3376. doi: 10.1371/journal.pone.0003376

Bennetzen, J. L., Schmutz, J., Wang, H., Percifield, R., Hawkins, J., Pontaroli, A. C., et al. (2012). Reference genome sequence of the model plant Setaria. Nat. Biotechnol. 30, 555-561. doi: 10.1038/nbt.2196

Bohra, A., Pandey, M. K., Jha, U. C., Singh, B., Singh, I. P., Datta, D., et al. (2014). Genomics-assisted breeding in four major pulse crops of developing countries: present status and prospects. Theor. Appl. Genet. 127, 1263-1291. doi: 10.1007/s00122-014-2301-3

Bonos, S. A., Clarke, B. B., and Meyer, W. A. (2006). Breeding for disease resistance in the major cool-season turfgrasses. Annu. Rev. Phytopathol. 44, 213-234. doi: 10.1146/annurev.phyto.44.070505.143338

Brazauskas, G., Xing, Y., Studer, B., Schejbel, B., Frei, U., Berg, P. R., et al. (2013). Identification of genomic loci associated with crown rust resistance in perennial ryegrass (Lolium perenne L.) divergently selected populations. Plant Sci. 208, 34-41. doi: 10.1016/j.plantsci.2013.02.017

Byrne, S., Czaban, A., Studer, B., Panitz, F., Bendixen, C., and Asp, T. (2013). Genome wide allele frequency fingerprints (GWAFFs) of populations via genotyping by sequencing. PLOS ONE 8:e57438. doi: 10.1371/journal.pone. 0057438

Byrne, S., Panitz, F., Hedegaard, J., Bendixen, C., Studer, B., Farrell, J. D., et al. (2011). "De novo genome sequencing of perennial ryegrass (Lolium perenne)," in Proceedings of the International Plant \& Animal Genome XX Conference, San Diego, CA.

Byrne, S. L., Nagy, I., Pfeifer, M., Armstead, I., Swain, S., Studer, B., et al. (2015). A synteny-based draft genome sequence of the forage grass Lolium perenne. Plant J. 84, 816-826. doi: 10.1111/tpj.13037

Cairns, J., Impa, S., O’Toole, J., Jagadish, S., and Price, A. (2011). Influence of the soil physical environment on rice (Oryza sativa L.) response to drought stress and its implications for drought research. Field Crops Res. 121, 303-310. doi: 10.1016/j.fcr.2011.01.012

Caldwell, D. G., McCallum, N., Shaw, P., Muehlbauer, G. J., Marshall, D. F., and Waugh, R. (2004). A structured mutant population for forward and reverse genetics in Barley (Hordeum vulgare L.). Plant J. 40, 143-150. doi: 10.1111/j. 1365-313X.2004.02190.x

Chagné, D., Bianco, L., Lawley, C., Micheletti, D., and Jacobs, J. M. (2015). "Methods for the design, implementation, and analysis of illumina infinium ${ }^{\mathrm{TM}}$
SNP assays in plants," in Plant Genotyping: Methods and Protocols, ed. J. Batley (New York, NY: Springer), 281-298.

Chapman, M. A. (2015). Transcriptome sequencing and marker development for four underutilized legumes. Appl. Plant Sci. 3, 1-5. doi: 10.3732/apps.1400111

Chen, H., Wang, L., Wang, S., Liu, C., Blair, M. W., and Cheng, X. (2015). Transcriptome sequencing of mung bean (Vigna radiate L.) genes and the identification of EST-SSR markers. PLOS ONE 10:e0120273. doi: 10.1371/ journal.pone.0120273

Choi, M., Scholl, U. I., Ji, W., Liu, T., Tikhonova, I. R., Zumbo, P., et al. (2009). Genetic diagnosis by whole exome capture and massively parallel DNA sequencing. Proc. Natl. Acad. Sci. U.S.A. 106, 19096-19101. doi: 10.1073/pnas. 0910672106

Chutimanitsakun, Y., Nipper, R. W., Cuesta-Marcos, A., Cistué, L., Corey, A., Filichkina, T., et al. (2011). Construction and application for QTL analysis of a Restriction Site Associated DNA (RAD) linkage map in barley. BMC Genomics 12:4. doi: 10.1186/1471-2164-12-4

Close, T. J., Bhat, P. R., Lonardi, S., Wu, Y., Rostoks, N., Ramsay, L., et al. (2009). Development and implementation of high-throughput SNP genotyping in barley. BMC Genomics 10:582. doi: 10.1186/1471-2164-10-582

Cobb, J. N., DeClerck, G., Greenberg, A., Clark, R., and McCouch, S. (2013). Next-generation phenotyping: requirements and strategies for enhancing our understanding of genotype-phenotype relationships and its relevance to crop improvement. Theor. Appl. Genet. 126, 867-887. doi: 10.1007/s00122-0132066-0

Comai, L., Young, K., Till, B. J., Reynolds, S. H., Greene, E. A., Codomo, C. A., et al. (2004). Efficient discovery of DNA polymorphisms in natural populations by Ecotilling. Plant J. 37, 778-786. doi: 10.1111/j.0960-7412.2003.01999.x

Consortium, I. B. G. S. (2012). A physical, genetic and functional sequence assembly of the barley genome. Nature 491, 711-716. doi: 10.1038/nature11543

Costa, J. M., Grant, O. M., and Chaves, M. M. (2013). Thermography to explore plant-environment interactions. J. Exp. Bot. 64, 3937-3949. doi: 10.1093/jxb/ ert029

Crossa, J., Pérez, P., Hickey, J., Burgueño, J., Ornella, L., Cerón-Rojas, J., et al. (2014). Genomic prediction in CIMMYT maize and wheat breeding programs. Heredity 112, 48-60. doi: 10.1038/hdy.2013.16

Czaban, A., Sharma, S., Byrne, S. L., Spannagl, M., Mayer, K. F., and Asp, T. (2015). Comparative transcriptome analysis within the Lolium/Festuca species complex reveals high sequence conservation. BMC Genomics 16:249. doi: 10.1186/s12864-015-1447-y

Daverdin, G., Bahri, B. A., Wu, X., Serba, D. D., Tobias, C., Saha, M. C., et al. (2014). Comparative relationships and chromosome evolution in switchgrass (Panicum virgatum) and its genomic model, foxtail millet (Setaria italica). Bioenergy Res. 8, 137-151. doi: 10.1371/journal.pone.0064594

de Alba, A. E. M., Moreno, A., Gabriel, M., Mallory, A. C., Christ, A., Bounon, R., et al. (2015). In plants, decapping prevents RDR6-dependent production of small interfering RNAs from endogenous mRNAs. Nucleic Acids Res. 43, 2902-2913. doi: 10.1093/nar/gkv119

Dierking, R., Azhaguvel, P., Kallenbach, R., Saha, M., Bouton, J., Chekhovskiy, K., et al. (2015). Linkage maps of a Mediterranean x Continental tall fescue (Festuca arundinacea) population and their comparative analysis with other Poaceae species. Plant Genome 7, 1-8.

Dinkins, R. D., Nagabhyru, P., Graham, M. A., Boykin, D., and Schardl, C. L. (2017). Transcriptome response of Lolium arundinaceum to its fungal endophyte Epichloë coenophiala. New Phytol. 213, 324-337. doi: 10.1111/nph. 14103

Dorn, K. M. (2017a). "Developing a genomic toolbox for the improvement of intermediate wheatgrass as a perennial grain crop," in Proceedings of the International Plant \& Animal Genome XXV Conference, San Diego, CA.

Dorn, K. M. (2017b). “The intermediate wheatgrass genome: a resource for understanding mechanisms of perenniality and accelerating the development of perennial crops," in Proceedings of the International Plant \& Animal Genome XXV Conference, San Diego, CA.

Elshire, R. J., Glaubitz, J. C., Sun, Q., Poland, J. A., Kawamoto, K., Buckler, E. S., et al. (2011). A robust, simple genotyping-by-sequencing (GBS) approach for high diversity species. PLoS ONE 6:e19379. doi: 10.1371/journal.pone.0019379

Ergon, Å., Fang, C., Jørgensen, Ø., Aamlid, T., and Rognli, O. (2006). Quantitative trait loci controlling vernalisation requirement, heading time and number of 
panicles in meadow fescue (Festuca pratensis Huds.). Theor. Appl. Genet. 112, 232-242. doi: 10.1007/s00122-005-0115-z

Fè, D., Ashraf, B. H., Pedersen, M. G., Janss, L., Byrne, S., Roulund, N., et al. (2016). Accuracy of genomic prediction in a commercial perennial ryegrass breeding program. Plant Genome 9, 1-12. doi: 10.3835/plantgenome2015.11.0110

Fè, D., Cericola, F., Byrne, S., Lenk, I., Ashraf, B. H., Pedersen, M. G., et al. (2015). Genomic dissection and prediction of heading date in perennial ryegrass. BMC Genomics 16:921. doi: 10.1186/s12864-015-2163-3

Flint, J., and Mackay, T. F. (2009). Genetic architecture of quantitative traits in mice, flies, and humans. Genome Res. 19, 723-733. doi: 10.1101/gr.086660.108

Forster, J., Hand, M., Cogan, N., Hayes, B., Spangenberg, G. C., and Smith, K. (2014). Resources and strategies for implementation of genomic selection in breeding of forage species. Crop Pasture Sci. 65, 1238-1247. doi: 10.1071/ CP13361

Fukuoka, S., Saka, N., Koga, H., Ono, K., Shimizu, T., Ebana, K., et al. (2009). Loss of function of a proline-containing protein confers durable disease resistance in rice. Science 325, 998-1001. doi: 10.1126/science.1175550

Gan, L., Di, R., Chao, Y., Han, L., Chen, X., Wu, C., et al. (2016). De novo transcriptome analysis for Kentucky Bluegrass dwarf mutants induced by space mutation. PLoS ONE 11:e0151768. doi: 10.1371/journal.pone.0151768

Goff, S. A., Ricke, D., Lan, T.-H., Presting, G., Wang, R., Dunn, M., et al. (2002). A draft sequence of the rice genome (Oryza sativa L. ssp. japonica). Science 296, 92-100. doi: 10.1126/science. 1068275

Goggin, F. L., Lorence, A., and Topp, C. N. (2015). Applying high-throughput phenotyping to plant-insect interactions: picturing more resistant crops. Curr. Opin. Insect Sci. 9, 69-76. doi: 10.1016/j.cois.2015.03.002

Grabherr, M. G., Haas, B. J., Yassour, M., Levin, J. Z., Thompson, D. A., Amit, I., et al. (2011). Full-length transcriptome assembly from RNA-Seq data without a reference genome. Nat. Biotechnol. 29, 644-652. doi: 10.1038/nbt.1883

Griffiths, S., Simmonds, J., Leverington, M., Wang, Y., Fish, L., Sayers, L., et al. (2012). Meta-QTL analysis of the genetic control of crop height in elite European winter wheat germplasm. Mol. Breed. 29, 159-171. doi: 10.1007/ s00122-009-1046-x

Grinberg, N. F., Lovatt, A., Hegarty, M., Lovatt, A., Skøt, K. P., Kelly, R., et al. (2016). Implementation of genomic prediction in Lolium perenne (L.) breeding populations. Front. Plant Sci. 7:133. doi: 10.3389/fpls.2016.00133

Hayes, B. J., Cogan, N. O., Pembleton, L. W., Goddard, M. E., Wang, J., Spangenberg, G. C., et al. (2013). Prospects for genomic selection in forage plant species. Plant Breed. 132, 133-143. doi: 10.1371/journal.pone.0059668

Heffner, E. L., Sorrells, M. E., and Jannink, J.-L. (2009). Genomic selection for crop improvement. Crop Sci. 49, 1-12. doi: 10.2135/cropsci2008.08.0512

Hegarty, M., Yadav, R., Lee, M., Armstead, I., Sanderson, R., Scollan, N., et al. (2013). Genotyping by RAD sequencing enables mapping of fatty acid composition traits in perennial ryegrass (Lolium perenne (L.). Plant Biotechnol. J. 11, 572-581. doi: 10.1111/pbi.12045

Henry, I. M., Nagalakshmi, U., Lieberman, M. C., Ngo, K. J., Krasileva, K. V., Vasquez-Gross, H., et al. (2014). Efficient genome-wide detection and cataloging of EMS-induced mutations using exome capture and nextgeneration sequencing. Plant Cell Online 26, 1382-1397. doi: 10.1105/tpc.113. 121590

Hirsch, C. D., Evans, J., Buell, C. R., and Hirsch, C. N. (2014). Reduced representation approaches to interrogate genome diversity in large repetitive plant genomes. Brief. Funct. Genomics 13, 257-267. doi: 10.1093/bfgp/elt051

Hohenlohe, P. A., Bassham, S., Etter, P. D., Stiffler, N., Johnson, E. A., and Cresko, W. A. (2010). Population genomics of parallel adaptation in threespine stickleback using sequenced RAD tags. PLoS Genet. 6:e1000862. doi: 10.1371/ journal.pgen.1000862

Holland, J. B. (2007). Genetic architecture of complex traits in plants. Curr. Opin. Plant Biol. 10, 156-161. doi: 10.1016/j.pbi.2007.01.003

Holtz, Y., Ardisson, M., Ranwez, V., Besnard, A., Leroy, P., Poux, G., et al. (2016). Genotyping by sequencing using specific allelic capture to build a high-density genetic map of durum wheat. PLOS ONE 11:e0154609. doi: 10.1371/journal. pone.0154609

Honig, J. A., Zelzion, E., Wagner, N. E., Kubik, C., Averello, V., Vaiciunas, J., et al. (2017). Microsatellite identification in perennial ryegrass using next-generation sequencing. Crop Sci. 57, 1-10. doi: 10.2135/cropsci2016.07.0608

Houle, D., Govindaraju, D. R., and Omholt, S. (2010). Phenomics: the next challenge. Nat. Rev. Genet. 11, 855-866. doi: 10.1038/nrg2897
Huang, X., and Han, B. (2014). Natural variations and genome-wide association studies in crop plants. Annu. Rev. Plant Biol. 65, 531-551. doi: 10.1146/ annurev-arplant-050213-035715

Huang, X., Wei, X., Sang, T., Zhao, Q., Feng, Q., Zhao, Y., et al. (2010). Genomewide association studies of 14 agronomic traits in rice landraces. Nat. Genet. 42, 961-967. doi: 10.1038/ng.695

Hudson, C. J., Kullan, A. R., Freeman, J. S., Faria, D. A., Grattapaglia, D., Kilian, A., et al. (2012). High synteny and colinearity among Eucalyptus genomes revealed by high-density comparative genetic mapping. Tree Genet. Genomes 8, 339-352. doi: 10.1007/s11295-011-0444-9

Humplík, J. F., Lazár, D., Husičková, A., and Spíchal, L. (2015). Automated phenotyping of plant shoots using imaging methods for analysis of plant stress responses-a review. Plant Methods 11:29. doi: 10.1186/s13007-0150072-8

Jannink, J.-L., Lorenz, A. J., and Iwata, H. (2010). Genomic selection in plant breeding: from theory to practice. Brief. Funct. Genomics 9, 166-177. doi: 10.1093/bfgp/elq001

Jensen, L. B., Andersen, J. R., Frei, U., Xing, Y., Taylor, C., Holm, P. B., et al. (2005). QTL mapping of vernalization response in perennial ryegrass (Lolium perenne L.) reveals co-location with an orthologue of wheat VRN1. Theor. Appl. Genet. 110, 527-536. doi: 10.1007/s00122-004-1865-8

Jespersen, D., Merewitz, E., Xu, Y., Honig, J., Bonos, S., Meyer, W., et al. (2016). Quantitative trait loci associated with physiological traits for heat tolerance in creeping bentgrass. Crop Sci. 56, 1314-1329. doi: 10.2135/cropsci2015.07.0428

Jia, J., Zhao, S., Kong, X., Li, Y., Zhao, G., He, W., et al. (2013). Aegilops tauschii draft genome sequence reveals a gene repertoire for wheat adaptation. Nature 496, 91-95. doi: 10.1038/nature12028

Kadaru, S. B., Yadav, A. S., Fjellstrom, R. G., and Oard, J. H. (2006). Alternative ecotilling protocol for rapid, cost-effective single-nucleotide polymorphism discovery and genotyping in rice (Oryza sativa L.). Plant Mol. Biol. Rep. 24, 3-22. doi: 10.1007/BF02914042

Kamphuis, L. G., Hane, J. K., Nelson, M. N., Gao, L., Atkins, C. A., and Singh, K. B. (2015). Transcriptome sequencing of different narrow-leafed lupin tissue types provides a comprehensive uni-gene assembly and extensive gene-based molecular markers. Plant Biotechnol. J. 13, 14-25. doi: 10.1111/pbi.12229

Kantarski, T., Larson, S., Zhang, X., DeHaan, L., Borevitz, J., Anderson, J., et al. (2017). Development of the first consensus genetic map of intermediate wheatgrass (Thinopyrum intermedium) using genotyping-by-sequencing. Theor. Appl. Genet. 130, 137-150. doi: 10.1007/s00122-016-2799-7

Khaembah, E. N., Irving, L. J., Thom, E. R., Faville, M. J., Easton, H. S., and Matthew, C. (2013). Leaf Rubisco turnover in a perennial ryegrass (Lolium perenne L.) mapping population: genetic variation, identification of associated QTL, and correlation with plant morphology and yield. J. Exp. Bot. 64, 1305-1316. doi: 10.1093/jxb/ers384

Kliebenstein, D. J. (2010). Systems biology uncovers the foundation of natural genetic diversity. Plant Physiol. 152, 480-486. doi: 10.1104/pp.109.149328

KöLliker, R., Boller, B., and Widmer, F. (2005). Marker assisted polycross breeding to increase diversity and yield in perennial ryegrass (Lolium perenne L.). Euphytica 146, 55-65. doi: 10.1007/s00122-011-1775-5

Kopecký, D., and Studer, B. (2014). Emerging technologies advancing forage and turf grass genomics. Biotechnol. Adv. 32, 190-199. doi: 10.1016/j.biotechadv. 2013.11.010

Kujur, A., Saxena, M. S., Bajaj, D., and Parida, S. K. (2013). Integrated genomics and molecular breeding approaches for dissecting the complex quantitative traits in crop plants. J. Biosci. 38, 971-987. doi: 10.1007/s12038-013-9388-6

Kundu, A., Chakraborty, A., Mandal, N. A., Das, D., Karmakar, P. G., Singh, N. K., et al. (2015). A restriction-site-associated DNA (RAD) linkage map, comparative genomics and identification of QTL for histological fibre content coincident with those for retted bast fibre yield and its major components in jute (Corchorus olitorius L., Malvaceae sl). Mol. Breed. 35:19. doi: 10.1007/s11032015-0249-x

Lai, K., Lorenc, M. T., Lee, H. C., Berkman, P. J., Bayer, P. E., Visendi, P., et al. (2015). Identification and characterization of more than 4 million intervarietal SNPs across the group 7 chromosomes of bread wheat. Plant Biotechnol. J. 13, 97-104. doi: 10.1111/pbi.12240

Lee, H., Gurtowski, J., Yoo, S., Nattestad, M., Marcus, S., Goodwin, S., et al. (2016). Third-generation sequencing and the future of genomics. bioRxiv. doi: 10.1101/ 048603 
Li, H., Hu, T., Amombo, E., and Fu, J. (2017). Transcriptome profilings of two tall fescue (Festuca arundinacea) cultivars in response to lead $(\mathrm{Pb})$ stress. BMC Genomics 18:145. doi: 10.1186/s12864-016-3479-3

Lin, Z., Cogan, N. O., Pembleton, L. W., Spangenberg, G. C., Forster, J. W., Hayes, B. J., et al. (2016). Genetic gain and inbreeding from genomic selection in a simulated commercial breeding program for perennial ryegrass. Plant Genome 9, 1-12. doi: 10.3835/plantgenome2015.06.0046

Lin, Z., Wang, J., Cogan, N. O., Pembleton, L. W., Badenhorst, P., Forster, J. W., et al. (2017). Optimizing resource allocation in a genomic breeding program for perennial ryegrass to balance genetic gain, cost, and inbreeding. Crop Sci. 57, 243-252. doi: 10.2135/cropsci2016.07.0577

Ling, H.-Q., Zhao, S., Liu, D., Wang, J., Sun, H., Zhang, C., et al. (2013). Draft genome of the wheat A-genome progenitor Triticum urartu. Nature 496, 87-90. doi: 10.1038/nature11997

Liu, S., Chen, H. D., Makarevitch, I., Shirmer, R., Emrich, S. J., Dietrich, C. R., et al. (2010). High-throughput genetic mapping of mutants via quantitative single nucleotide polymorphism typing. Genetics 184, 19-26. doi: 10.1534/genetics. 109.107557

Lorenz, A. J., Chao, S., Asoro, F. G., Heffner, E. L., Hayashi, T., Iwata, H., et al. (2011). Genomic selection in plant breeding: knowledge and prospects. $A d v$. Agron. 110, 77-123. doi: 10.1016/B978-0-12-385531-2.00002-5

Losos, J. B., Arnold, S. J., Bejerano, G., Brodie, E. III, Hibbett, D., Hoekstra, H. E., et al. (2013). Evolutionary biology for the 21st century. PLoS Biol. 11:e1001466. doi: 10.1371/journal.pbio.1001466

Lou, Y., Hu, L., Chen, L., Sun, X., Yang, Y., Liu, H., et al. (2015). Association analysis of simple sequence repeat (SSR) markers with agronomic traits in tall fescue (Festuca arundinacea Schreb.). PLoS ONE 10:e0133054. doi: 10.1371/journal. pone. 0133054

Lu, T., Lu, G., Fan, D., Zhu, C., Li, W., Zhao, Q., et al. (2010). Function annotation of the rice transcriptome at single-nucleotide resolution by RNA-seq. Genome Res. 20, 1238-1249. doi: 10.1101/gr.106120.110

Ma, Y., Mao, S.-L., Chen, G.-Y., Liu, Y.-X., Wei, L., Wei, Y.-M., et al. (2014). QTLs for waterlogging tolerance at germination and seedling stages in population of recombinant inbred lines derived from a cross between synthetic and cultivated wheat genotypes. J. Integr. Agric. 13, 31-39. doi: 10.1016/S2095-3119(13) 60354-8

Ma, Y., Shukla, V., and Merewitz, E. B. (2017). Transcriptome analysis of creeping bentgrass exposed to drought stress and polyamine treatment. PLOS ONE 12:e0175848. doi: 10.1371/journal.pone.0175848

Mahuku, G., Chen, J., Shrestha, R., Narro, L. A., Guerrero, K. V. O., Arcos, A. L., et al. (2016). Combined linkage and association mapping identifies a major QTL (qRtsc8-1), conferring tar spot complex resistance in maize. Theor. Appl. Genet. 129, 1217-1229. doi: 10.1007/s00122-016-2698-y

Marcussen, T., Sandve, S. R., Heier, L., Wulff, B. B., Steuernagel, B., Mayer, K. F., et al. (2014). A chromosome-based draft sequence of the hexaploid bread wheat (Triticum aestivum) genome. Science 345:1251788. doi: 10.1126/science. 1251788

Mascher, M., Richmond, T. A., Gerhardt, D. J., Himmelbach, A., Clissold, L., Sampath, D., et al. (2013). Barley whole exome capture: a tool for genomic research in the genus Hordeum and beyond. Plant J. 76, 494-505. doi: 10.1111/ tpj. 12294

Mason, A. S. (2015). "Challenges of genotyping polyploid species," in Plant Genotyping: Methods and Protocols, ed. J. Batley (New York, NY: Springer), 161-168.

Mayer, K. F., Taudien, S., Martis, M., Šimková, H., Suchánková, P., Gundlach, H., et al. (2009). Gene content and virtual gene order of barley chromosome $1 \mathrm{H}$. Plant Physiol. 151, 496-505. doi: 10.1104/pp.109.142612

McMullen, M. D., Kresovich, S., Villeda, H. S., Bradbury, P., Li, H., Sun, Q., et al. (2009). Genetic properties of the maize nested association mapping population. Science 325, 737-740. doi: 10.1126/science. 1174320

Mejlhede, N., Kyjovska, Z., Backes, G., Burhenne, K., Rasmussen, S. K., and Jahoor, A. (2006). EcoTILLING for the identification of allelic variation in the powdery mildew resistance genes mlo and Mla of barley. Plant Breed. 125, 461-467. doi: 10.1111/j.1439-0523.2006.01226.x

Meuwissen, T., Hayes, B., and Goddard, M. (2001). Prediction of total genetic value using genome-wide dense marker maps. Genetics 157, 1819-1829.

Mochida, K., and Shinozaki, K. (2010). Genomics and bioinformatics resources for crop improvement. Plant Cell Physiol. 51, 497-523. doi: 10.1093/pcp/pcq027
Morris, G. P., Ramu, P., Deshpande, S. P., Hash, C. T., Shah, T., Upadhyaya, H. D., et al. (2013). Population genomic and genome-wide association studies of agroclimatic traits in sorghum. Proc. Natl. Acad. Sci. U.S.A. 110, 453-458. doi: 10.1073/pnas. 1215985110

Mudalkar, S., Golla, R., Ghatty, S., and Reddy, A. R. (2014). De novo transcriptome analysis of an imminent biofuel crop, Camelina sativa L. using Illumina GAIIX sequencing platform and identification of SSR markers. Plant Mol. Biol. 84, 159-171. doi: 10.1007/s11103-013-0125-1

Muir, P., Li, S., Lou, S., Wang, D., Spakowicz, D. J., Salichos, L., et al. (2016). The real cost of sequencing: scaling computation to keep pace with data generation. Genome Biol. 17:53. doi: 10.1186/s13059-016-0917-0

Munoz, P. R. (2017). "Genomic selection by pooled genotyping," in Proceedings of the International Plant \& Animal Genome XXV Conference, San Diego, CA.

Muylle, H., Baert, J., Van Bockstaele, E., Pertijs, J., and Roldàn-Ruiz, I. (2005). Four QTLs determine crown rust (Puccinia coronata f. sp. lolii) resistance in a perennial ryegrass (Lolium perenne) population. Heredity 95, 348-357. doi: $10.1038 /$ sj.hdy. 6800729

Nagarajan, N., and Pop, M. (2013). Sequence assembly demystified. Nat. Rev. Genet. 14, 157-167. doi: 10.1038/nrg3367

Ng, S. B., Turner, E. H., Robertson, P. D., Flygare, S. D., Bigham, A. W., Lee, C., et al. (2009). Targeted capture and massively parallel sequencing of 12 human exomes. Nature 461, 272-276. doi: 10.1038/nature08250

Nogué, F., Mara, K., Collonnier, C., and Casacuberta, J. M. (2016). Genome engineering and plant breeding: impact on trait discovery and development. Plant Cell Rep. 35, 1475-1486. doi: 10.1007/s00299-016-1993-z

Obsa, B. T., Eglinton, J., Coventry, S., March, T., Langridge, P., and Fleury, D. (2016). Genetic analysis of developmental and adaptive traits in three doubled haploid populations of barley (Hordeum vulgare L.). Theor. Appl. Genet. 129, 1139-1151. doi: 10.1007/s00122-016-2689-z

Oliver, R. E., Lazo, G. R., Lutz, J. D., Rubenfield, M. J., Tinker, N. A., Anderson, J. M., et al. (2011). Model SNP development for complex genomes based on hexaploid oat using high-throughput 454 sequencing technology. BMC Genomics 12:77. doi: 10.1186/1471-2164-12-77

Orr, H. A. (2005). The genetic theory of adaptation: a brief history. Nat. Rev. Genet. 6, 119-127. doi: $10.1038 / \mathrm{nrg} 1523$

Owens, C. (2015). "Comparative mapping of the muscadine grape (Vitis rotundifolia) and the European bunch grape (V. vinifera) shows a high level of synteny between the two species," in Proceedings of the International Plant \& Animal Genome XXIII Conference, San Diego, CA.

Paget, M., Armstead, I. P., Humphreys, M. O., Thorogood, D., Turner, L. B., and Roderick, H. W. (2014). QTL analysis of crown rust resistance in perennial ryegrass-implications for breeding. Int. Turfgrass Soc. Res. J. 9, 218-223.

Paina, C., Byrne, S. L., Studer, B., Rognli, O. A., and Asp, T. (2016). Using a candidate gene-based genetic linkage map to identify QTL for winter survival in perennial ryegrass. PLoS ONE 11:e0152004. doi: 10.1371/journal.pone.0152004

Paolucci, I., Gaudet, M., Jorge, V., Beritognolo, I., Terzoli, S., Kuzminsky, E., et al. (2010). Genetic linkage maps of Populus alba L. and comparative mapping analysis of sex determination across Populus species. Tree Genet. Genomes 6, 863-875. doi: 10.1007/s11295-010-0297-7

Pearson, A., Cogan, N. O., Baillie, R. C., Hand, M. L., Bandaranayake, C. K., Erb, S., et al. (2011). Identification of QTLs for morphological traits influencing waterlogging tolerance in perennial ryegrass (Lolium perenne L.). Theor. Appl. Genet. 122, 609-622. doi: 10.1007/s00122-010-1473-8

Peleman, J. D., and van der Voort, J. R. (2003). Breeding by design. Trends Plant Sci. 8, 330-334. doi: 10.1016/S1360-1385(03)00134-1

Pembleton, L. W., Drayton, M. C., Bain, M., Baillie, R. C., Inch, C., Spangenberg, G. C., et al. (2016). Targeted genotyping-by-sequencing permits cost-effective identification and discrimination of pasture grass species and cultivars. Theor. Appl. Genet. 129, 991-1005. doi: 10.1007/s00122-016-2678-2

Pérez-de-Castro, A., Vilanova, S., Cañizares, J., Pascual, L., Blanca, J., Díez, M., et al. (2012). Application of genomic tools in plant breeding. Curr. Genomics 13, 179-195. doi: 10.2174/138920212800543084

Pfeifer, M., Martis, M., Asp, T., Mayer, K. F., Lübberstedt, T., Byrne, S., et al. (2013). The perennial ryegrass GenomeZipper: targeted use of genome resources for comparative grass genomics. Plant Physiol. 161, 571-582. doi: 10.1104/pp.112. 207282

Pfender, W., Saha, M., Johnson, E., and Slabaugh, M. (2011). Mapping with RAD (restriction-site associated DNA) markers to rapidly identify QTL for 
stem rust resistance in Lolium perenne. Theor. Appl. Genet. 122, 1467-1480. doi: 10.1007/s00122-011-1546-3

Pingault, L., Choulet, F., Alberti, A., Glover, N., Wincker, P., Feuillet, C., et al. (2015). Deep transcriptome sequencing provides new insights into the structural and functional organization of the wheat genome. Genome Biol. 16:29. doi: 10.1186/s13059-015-0601-9

Pittman, J. J., Arnall, D. B., Interrante, S. M., Wang, N., Raun, W. R., and Butler, T. J. (2016). Bermudagrass, wheat, and tall fescue crude protein forage estimation using mobile-platform, active-spectral and canopy-height data. Crop Sci. 56, 870-881. doi: 10.2135/cropsci2015.05.0274

Poland, J. (2015). Breeding-assisted genomics. Curr. Opin. Plant Biol. 24, 119-124. doi: 10.1016/j.pbi.2015.02.009

Poland, J. A., Brown, P. J., Sorrells, M. E., and Jannink, J.-L. (2012). Development of high-density genetic maps for barley and wheat using a novel two-enzyme genotyping-by-sequencing approach. PLOS ONE 7:e32253. doi: 10.1371/journal. pone.0032253

Poursarebani, N., Ariyadasa, R., Zhou, R., Schulte, D., Steuernagel, B., Martis, M. M., et al. (2013). Conserved synteny-based anchoring of the barley genome physical map. Funct. Integr. Genomics 13, 339-350. doi: 10.1007/s10142-0130327-2

Pradhan, S. K., Nayak, D. K., Mohanty, S., Behera, L., Barik, S. R., Pandit, E., et al. (2015). Pyramiding of three bacterial blight resistance genes for broad-spectrum resistance in deepwater rice variety, Jalmagna. Rice 8:19. doi: 10.1186/s12284015-0051-8

Raines, C. A. (2011). Increasing photosynthetic carbon assimilation in C3 plants to improve crop yield: current and future strategies. Plant Physiol. 155, 36-42. doi: $10.1104 /$ pp.110.168559

Rajicic, T. S., Lübberstedt, T., Jensen, L. B., Scholz, U., Weber, W. E., Graner, A., et al. (2015). "Single nucleotide polymorphism (SNP) markers for allele quantification in Lolium (Poaceae): development and first applications," in Molecular Breeding of Forage and Turf, eds H. Budak and G. Spangenberg (New York, NY: Springer), 143-163.

Rascher, U., Blossfeld, S., Fiorani, F., Jahnke, S., Jansen, M., Kuhn, A. J., et al. (2011). Non-invasive approaches for phenotyping of enhanced performance traits in bean. Funct. Plant Biol. 38, 968-983. doi: 10.1071/ FP11164

Rinn, J. L., and Chang, H. Y. (2012). Genome regulation by long noncoding RNAs. Annu. Rev. Biochem. 81, 145-166. doi: 10.1146/annurev-biochem-051410092902

Ruperao, P., and Edwards, D. (2015). "Bioinformatics: identification of markers from next-generation sequence data," in Plant Genotyping, ed. J. Batley (New York, NY: Springer), 29-47. doi: 10.1007/978-1-4939-1966-6_3

Ruttink, T., Haegeman, A., van Parijs, F., Van Glabeke, S., Muylle, H., Byrne, S., et al. (2015). "Genetic diversity in candidate genes for developmental traits and cell wall characteristics in perennial ryegrass (Lolium perenne)," in Molecular Breeding of Forage and Turf, eds H. Budak and G. Spangenberg (New York, NY: Springer), 93-109.

Saha, M. C., Mian, R., Zwonitzer, J. C., Chekhovskiy, K., and Hopkins, A. A. (2005). An SSR- and AFLP-based genetic linkage map of tall fescue (Festuca arundinacea Schreb.). Theor. Appl. Genet. 110, 323-336. doi: 10.1007/s00122004-1843-1

Salvi, S., and Tuberosa, R. (2015). The crop QTLome comes of age. Curr. Opin. Biotechnol. 32, 179-185. doi: 10.1016/j.copbio.2015.01.001

Sato, K., Nankaku, N., and Takeda, K. (2009). A high-density transcript linkage map of barley derived from a single population. Heredity 103, 110-117. doi: 10.1038/hdy.2009.57

Satovic, Z., Avila, C. M., Cruz-Izquierdo, S., Díaz-Ruíz, R., García-Ruíz, G. M., Palomino, C., et al. (2013). A reference consensus genetic map for molecular markers and economically important traits in faba bean (Vicia faba L.). BMC Genomics 14:932. doi: 10.1186/1471-2164-14-932

Schadt, E. E., Monks, S. A., Drake, T. A., Lusis, A. J., Che, N., Colinayo, V., et al. (2003). Genetics of gene expression surveyed in maize, mouse and man. Nature 422, 297-302. doi: 10.1038/nature01434

Schejbel, B., Jensen, L., Asp, T., Xing, Y., and Lübberstedt, T. (2008). Mapping of QTL for resistance to powdery mildew and resistance gene analogues in perennial ryegrass. Plant Breed. 127, 368-375. doi: 10.1111/j.1439-0523.2007. 01477.x
Schmutz, J., McClean, P. E., Mamidi, S., Wu, G. A., Cannon, S. B., Grimwood, J., et al. (2014). A reference genome for common bean and genome-wide analysis of dual domestications. Nat. Genet. 46, 707-713. doi: 10.1038/ng.3008

Sheeja, T., Deepa, K., Santhi, R., and Sasikumar, B. (2015). Comparative transcriptome analysis of two species of Curcuma contrasting in a high-value compound curcumin: insights into genetic basis and regulation of biosynthesis. Plant Mol. Biol. Rep. 33, 1825-1836. doi: 10.1007/s11105-015-0878-6

Sim, S., Diesburg, K., Casler, M., and Jung, G. (2007). Mapping and comparative analysis of QTL for crown rust resistance in an Italian $\times$ perennial ryegrass population. Phytopathology 97, 767-776. doi: 10.1094/PHYTO-97-6-0767

Simeão Resende, R. M., Casler, M. D., and Vilela de Resende, M. D. (2014). Genomic selection in forage breeding: accuracy and methods. Crop Sci. 54, 143-156. doi: 10.2135/cropsci2013.05.0353

Skøt, L., Humphreys, M. O., Armstead, I., Heywood, S., Skøt, K. P., Sanderson, R., et al. (2005). An association mapping approach to identify flowering time genes in natural populations of Lolium perenne (L.). Mol. Breed. 15, 233-245. doi: 10.1007/s11032-004-4824-9

Slavov, G. T., Nipper, R., Robson, P., Farrar, K., Allison, G. G., Bosch, M., et al. (2014). Genome-wide association studies and prediction of 17 traits related to phenology, biomass and cell wall composition in the energy grass Miscanthus sinensis. New Phytol. 201, 1227-1239. doi: 10.1111/nph.12621

Stevens, P. (2001). Angiosperm Phylogeny Website. Version 12, July 2012. St Louis, MO: University of Missouri,

Talukder, S., Azhaguvel, P., Mukherjee, S., Young, C., Tang, Y., Krom, N., et al. (2015). De novo assembly and characterization of tall fescue transcriptome under water stress. Plant Genome 8:1-13. doi: 10.3835/plantgenome2014.09. 0050

Talukder, S. K., Babar, M. A., Vijayalakshmi, K., Poland, J., Prasad, P. V., Bowden, R., et al. (2014). Mapping QTL for the traits associated with heat tolerance in wheat (Triticum aestivum L.). BMC Genetics 15:97. doi: 10.1186/ s12863-014-0097-4

Tester, M., and Langridge, P. (2010). Breeding technologies to increase crop production in a changing world. Science 327, 818-822. doi: 10.1126/science. 1183700

Till, B. J., Burtner, C., Comai, L., and Henikoff, S. (2004). Mismatch cleavage by single-strand specific nucleases. Nucleic Acids Res. 32, 2632-2641. doi: 10.1093/ nar/gkh599

Till, B. J., Reynolds, S. H., Greene, E. A., Codomo, C. A., Enns, L. C., Johnson, J. E., et al. (2003). Large-scale discovery of induced point mutations with high-throughput TILLING. Genome Res. 13, 524-530. doi: 10.1101/gr.977903

Torre, S., Tattini, M., Brunetti, C., Fineschi, S., Fini, A., Ferrini, F., et al. (2014). RNA-Seq Analysis of Quercus pubescens leaves: de novo transcriptome assembly, annotation and functional markers development. PLoS ONE 9:e112487. doi: 10.1371/journal.pone.0112487

Tuberosa, R., and Salvi, S. (2006). Genomics-based approaches to improve drought tolerance of crops. Trends Plant Sci. 11, 405-412. doi: 10.1016/j.tplants.2006 .06 .003

Turner, L. B., Cairns, A. J., Armstead, I. P., Ashton, J., Skøt, K., Whittaker, D., et al. (2006). Dissecting the regulation of fructan metabolism in perennial ryegrass (Lolium perenne) with quantitative trait locus mapping. New Phytol. 169, 45-58. doi: 10.1111/j.1469-8137.2005.01575.x

Varshney, R. K. (2015). "A reference genome and hapmap for pearl millet (Pennisetum glaucum)," in Proceedings of the International Plant \& Animal Genome XXIII Conference, San Diego, CA.

Varshney, R. K., Terauchi, R., and McCouch, S. R. (2014). Harvesting the promising fruits of genomics: applying genome sequencing technologies to crop breeding. PLoS Biol. 12:e1001883. doi: 10.1371/journal.pbio.1001883

Varshney, R. K., and Tuberosa, R. (2007). Genomics-Assisted Crop Improvement: Genomics Applications in Crops, Vol. 2. Berlin: Springer Science \& Business Media.

Velmurugan, J., Mollison, E., Barth, S., Marshall, D., Milne, L., Creevey, C. J., et al. (2016). An ultra-high density genetic linkage map of perennial ryegrass (Lolium perenne) using genotyping by sequencing (GBS) based on a reference shotgun genome assembly. Ann. Bot. 118, 71-87. doi: 10.1093/aob/mcw081

Venuprasad, R., Bool, M., Quiatchon, L., Cruz, M. S., Amante, M., and Atlin, G. (2012). A large-effect QTL for rice grain yield under upland drought stress on chromosome 1. Mol. Breed. 30, 535-547. doi: 10.1186/1471-2156-15-63 
Vogel, J. P., Garvin, D. F., Mockler, T. C., Schmutz, J., Rokhsar, D., Bevan, M. W., et al. (2010). Genome sequencing and analysis of the model grass Brachypodium distachyon. Nature 463, 763-768. doi: 10.1038/nature08747

Wang, F., Singh, R., Genovesi, A. D., Wai, C. M., Huang, X., Chandra, A., et al. (2015). Sequence-tagged high-density genetic maps of Zoysia japonica provide insights into Chloridoideae genome evolution. Plant J. 82, 744-757. doi: $10.1111 /$ tpj. 12842

Wang, Y., Yang, C., Jin, Q., Zhou, D., Wang, S., Yu, Y., et al. (2015). Genome-wide distribution comparative and composition analysis of the SSRs in Poaceae. BMC Genet. 16:18. doi: 10.1186/s12863-015-0178-z

Wang, J., Sun, J., Liu, D., Yang, W., Wang, D., Tong, Y., et al. (2008). Analysis of Pina and Pinb alleles in the micro-core collections of Chinese wheat germplasm by Ecotilling and identification of a novel Pinb allele. J. Cereal Sci. 48, 836-842. doi: 10.1016/j.jcs.2008.06.005

Wang, S., Wong, D., Forrest, K., Allen, A., Chao, S., Huang, B. E., et al. (2014). Characterization of polyploid wheat genomic diversity using a high-density 90 000 single nucleotide polymorphism array. Plant Biotechnol. J. 12, 787-796. doi: $10.1111 /$ pbi.12183

Wang, X., Zhao, L., Eaton, D., Li, D., and Guo, Z. (2013). Identification of SNP markers for inferring phylogeny in temperate bamboos (Poaceae: Bambusoideae) using RAD sequencing. Mol. Ecol. Resour. 13, 938-945. doi: 10.1111/1755-0998.12136

Wang, Z., Gerstein, M., and Snyder, M. (2009). RNA-Seq: a revolutionary tool for transcriptomics. Nat. Rev. Genet. 10, 57-63. doi: 10.1038/nrg2484

Weigel, D., and Mott, R. (2009). The 1001 genomes project for Arabidopsis thaliana. Genome Biol. 10:107. doi: 10.1186/gb-2009-10-5-107

Winfield, M. O., Wilkinson, P. A., Allen, A. M., Barker, G. L., Coghill, J. A., Burridge, A., et al. (2012). Targeted re-sequencing of the allohexaploid wheat exome. Plant Biotechnol. J. 10, 733-742. doi: 10.1111/j.1467-7652.2012.00713.x

Wu, J., Li, L.-T., Li, M., Khan, M. A., Li, X.-G., Chen, H., et al. (2014). Highdensity genetic linkage map construction and identification of fruit-related QTLs in pear using SNP and SSR markers. J. Exp. Bot. 65, 5771-5781. doi: 10.1093/jxb/eru311

Wu, Q.-H., Chen, Y.-X., Zhou, S.-H., Fu, L., Chen, J.-J., Xiao, Y., et al. (2015). High-Density Genetic Linkage Map Construction and QTL Mapping of Grain Shape and Size in the Wheat Population Yanda1817 $\times$ Beinong6. PLoS ONE 10:e0118144. doi: 10.1371/journal.pone.0118144

Xie, B.-B., Li, D., Shi, W.-L., Qin, Q.-L., Wang, X.-W., Rong, J.-C., et al. (2015). Deep RNA sequencing reveals a high frequency of alternative splicing events in the fungus Trichoderma longibrachiatum. BMC Genomics 16:54. doi: 10.1186/ s12864-015-1251-8

Xie, W., Feng, Q., Yu, H., Huang, X., Zhao, Q., Xing, Y., et al. (2010). Parentindependent genotyping for constructing an ultrahigh-density linkage map based on population sequencing. Proc. Natl. Acad. Sci. U.S.A. 107, 10578-10583. doi: 10.1073/pnas.1005931107

Xing, Y., and Zhang, Q. (2010). Genetic and molecular bases of rice yield. Annu. Rev. Plant Biol. 61, 421-442. doi: 10.1146/annurev-arplant-042809-112209
Xu, B., Ohtani, M., Yamaguchi, M., Toyooka, K., Wakazaki, M., Sato, M., et al. (2014). Contribution of NAC transcription factors to plant adaptation to land. Science 343, 1505-1508. doi: 10.1126/science.1248417

Xu, Y. B., McCouch, S. R., and Zhang, Q. F. (2005). How can we use genomics to improve cereals with rice as a reference genome? Plant Mol. Biol. 59, 7-26. doi: 10.1007/s11103-004-4681-2

Yates, S. A., Swain, M. T., Hegarty, M. J., Chernukin, I., Lowe, M., Allison, G. G., et al. (2014). De novo assembly of red clover transcriptome based on RNASeq data provides insight into drought response, gene discovery and marker identification. BMC Genomics 15:453. doi: 10.1186/1471-2164-15-453

Yu, J., Holland, J. B., McMullen, M. D., and Buckler, E. S. (2008). Genetic design and statistical power of nested association mapping in maize. Genetics 178, 539-551. doi: 10.1534/genetics.107.074245

Yu, J., Hu, S., Wang, J., Wong, G. K.-S., Li, S., Liu, B., et al. (2002). A draft sequence of the rice genome (Oryza sativa L. ssp. indica). Science 296, 79-92.

Yu, X., Bai, G., Liu, S., Luo, N., Wang, Y., Richmond, D. S., et al. (2013). Association of candidate genes with drought tolerance traits in diverse perennial ryegrass accessions. J. Exp. Bot. 64, 1537-1551. doi: 10.1093/jxb/ ert018

Yu, X., Pijut, P. M., Byrne, S., Asp, T., Bai, G., and Jiang, Y. (2015). Candidate gene association mapping for winter survival and spring regrowth in perennial ryegrass. Plant Sci. 235, 37-45. doi: 10.1016/j.plantsci.2015. 03.003

Zeng, B., Yan, H., Liu, X., Zang, W., Zhang, A., Zhou, S., et al. (2017). Genomewide association study of rust traits in orchardgrass using SLAF-seq technology. Hereditas 154:5. doi: 10.1186/s41065-017-0027-3

Zhang, B., Ye, W., Ren, D., Tian, P., Peng, Y., Gao, Y., et al. (2015). Genetic analysis of flag leaf size and candidate genes determination of a major QTL for flag leaf width in rice. Rice 8:39. doi: 10.1186/s12284-014-0039-9

Zhao, X., Huang, L., Zhang, X., Wang, J., Yan, D., Li, J., et al. (2016). Construction of high-density genetic linkage map and identification of flowering-time QTLs in orchardgrass using SSRs and SLAF-seq. Sci. Rep. 6:29345. doi: 10.1038/ srep29345

Zimin, A. (2016). "Assembly of the $4.5 \mathrm{~Gb}$ Ancestral Wheat D-Genome from Hybrid PacBio and Illumina Data," in Proceedings of the International Plant \& Animal Genome XXIV Conference, San Diego, CA.

Conflict of Interest Statement: The authors declare that the research was conducted in the absence of any commercial or financial relationships that could be construed as a potential conflict of interest.

Copyright (c) 2017 Talukder and Saha. This is an open-access article distributed under the terms of the Creative Commons Attribution License (CC BY). The use, distribution or reproduction in other forums is permitted, provided the original author(s) or licensor are credited and that the original publication in this journal is cited, in accordance with accepted academic practice. No use, distribution or reproduction is permitted which does not comply with these terms. 